Session S1F

\title{
2D AND 3D INTRODUCTORY PROCESSES IN VIRTUAL GROUPS
}

\author{
Tony Clear' and Mats Daniels ${ }^{2}$
}

\begin{abstract}
This paper reports upon a collaborative learning trial conducted in 2002 between students at Auckland University of Technology New Zealand and Uppsala University Sweden.
\end{abstract}

The trial design included an initial phase in which virtual groups became acquainted, using different modes of cybericebreaker, and a subsequent phase with a common task involving group decision making - evaluating and ranking the different icebreaker experiences.

The software used in the trial comprised 1) a custom developed web-based groupware database, and 2) a Java $3 D$ application, employing configurable avatars, which could be manipulated in a virtual world. Each of these applications supported icebreaking activities intended to establish trust between virtual group members, the latter in $3 D$ mode, and the former in $2 D$ mode.

The trial process and the software are initially outlined. The evaluation strategy, and approaches to data analysis are then discussed, and the paper concludes with a report of preliminary findings from the trial.

Index Terms - computer science education, virtual groups, web software, undergraduate research experiences.

\section{INTRODUCTION}

A collaborative learning trial conducted between students at Auckland University of Technology New Zealand and Uppsala University Sweden took place in semester two of 2002 , and required students subdivided into groups comprising members from each location, to complete a common task over a period of some six weeks.

The task involved two phases of activity. In the first phase students were to introduce themselves using different modes of cyber-icebreaker. In the second phase of the trial students were to individually rank their preferences for the alternative icebreakers, and then to collaborate to achieve an overall group consensus over these rankings.

The trial design therefore included an initial phase intended to enable the virtual groups to become acquainted with one another, and a subsequent phase with a common task involving group decision making - evaluating and ranking the different icebreaker experiences.

The software used in the trial comprised 1) a custom developed web-based groupware database, and 2) a Java 3D application based yon a client server design, employing configurable avatars, which could be manipulated in a virtual world. Each of these applications supported icebreaking activities by virtual group members, the latter in $3 \mathrm{D}$ mode, and the former in $2 \mathrm{D}$ mode.

This trial has taken place as one in a series within a longerterm action research programme. The use of a cyber icebreaker as a means of establishing trust within virtual groups and an evaluation of the contrast between $2 D$ and $3 D$ environments, have been some of the research goals of this collaborative trial.

The paper outlines the trial process and the nature of the software used. The evaluation strategy, and approaches to data analysis are discussed, and the paper concludes with a report of preliminary findings from the trial.

\section{The Collaborative Trial Process}

The trial consisted of a series of sequential and interdependent steps conducted by students at each location. The students had not previously met, and were assigned to groups, which spanned both locations but comprised one or more subgroups at each location. Students worked asynchronously given the 12-hour time difference between universities, and the different days and session times for the New Zealand classes, which included three separate sections of students. Some 125 students in all participated in the trial.

In previous trials $[1,3,4]$ it had been observed that text and graphics were somewhat limited in the ability they provided for students to represent themselves online. To provide a stronger form of "telepresence" [10] an undergraduate capstone project had been undertaken to develop a 3D cyber icebreaker application [5] using Avatars to represent the self online. It was hoped that this would afford a more multi dimensional means of representing the self in cyberspace. The collaborative trial therefore had a quasi-experimental design in which students used one of two forms of icebreaker; the forms based icebreaker used in previous trials [4] and the newly developed avatar based icebreaker. The trial process included student evaluations of the two icebreakers.

The trial steps for the first two weeks involved students familiarizing themselves with the applications and

\footnotetext{
1 Tony Clear, Auckland University of Technology, School of Information Technology, Private Bag 92006, Auckland, New Zealand, Tony.Clear@aut.ac.nz

2 Mats Daniels, Department of Computer Systems, Uppsaia University, Box 325, 751 05, Uppsaia, Sweden, Matsd@docs.uu.se
} 


\section{Session S1F}

completing the steps required in performing their introductions. For the forms based application this was a sequential and linear process, with students at each location working interdependently. The avatar based icebreaker had a slightly looser format, with students configuring their personal avatars, familiarizing themselves with the application and then engaging with the virtual room and their colleagues as they saw fit. At the end of each week students were also to post a progress report indicating how the trial was proceeding. The icebreaker phase was concluded with an online evaluation conducted through the web-based groupware database, in which students indicated their preferred mode of icebreaker.

The trial was interrupted at this stage by a two-week break to accommodate holidays for the New Zealand students. Subsequently subgroups were to meet and had to agree and post a preference ranking for their overall group based upon the individual preference rankings derived from the icebreaker evaluation stage. Once all subgroups for a group had completed their postings, the students vere asked to compare the postings for consistency and then complete a final online evaluation of the trial itself. The last session was reserved for an in-class review of the trial and what had been learnt from the exercise.

The role of the authors in the trial were as principal investigators at each site, with colleagues Michael Carlson co-coordinating activities operationally at the Uppsala site and Kitty Ko and Diana Kassabova supervising in-class activities with Auckland students. Tony Clear undertook oversight of the technology at the Auckland site, with the servers for the trial being hosted at Auckland University of Technology.

\section{THE WEB SOFTWARE}

Two discrete applications were used in the trial. The webbased groupware database had been developed as a prototype in Lotus Notes. Its main functionality included a forms-based icebreaker application, an online progress reporting feature [1], online evaluation forms, a threaded discussion area, facilities to upload/download files and links to websites, and features for online ranking and comparisons.

The avatar-based icebreaker had been developed as a capstone student project [5], and represented a novel Java 3D application to support icebreaking by global virtual groups using avatars, operating in an asynchronous mode. The underlying design philosophy was based upon a dramatic model, inspired in part by the Stage-struck product [9] with the user acting as 'puppet-master' for their personal avatar 'puppet' represented as a LEGO'M person, rather than using any form of artificial intelligence. With a set of predefined actions for avatars, threaded discussion and a playback feature, the software supports remote and repeated contributions to and viewing of, a developing 3D 'conversation'.

\section{$0-7803-7961-6 / 03 / \$ 17.00 @ 2003$ IEEE}

The description in this section will focus mainly upon the avatar-based software, as the design concept for this application (as opposed to the Lotus Notes ${ }^{\mathrm{TM}}$ groupware application based upon forms and views) is quite distinctive. Conceptually the design has incorporated a client-server architecture, with the virtual world residing on the client to reduce the network load, to the database containing avatar configuration and position information residing on the server. This system architecture is depicted in figure 1 below:

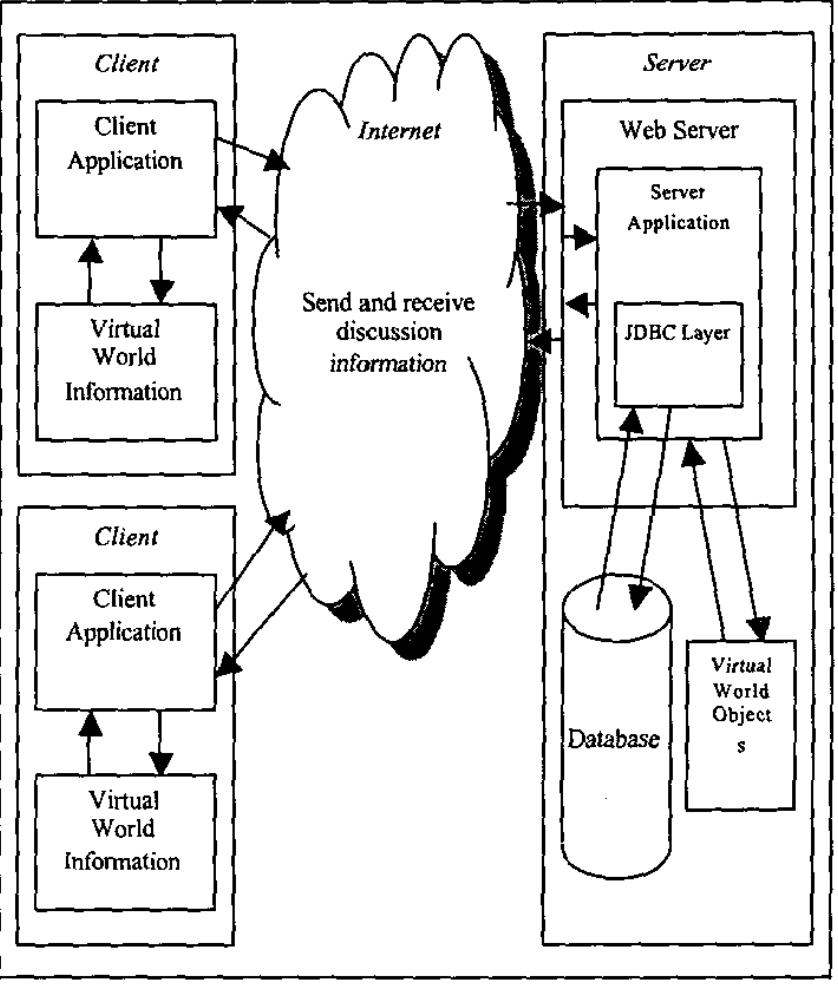

FIGURE 1

CYBER ICEBREAKER SYSTEM ARCHITECTURE [7]

The functionality provided by the application includes the following set of features:

- A security management subsystem providing for individual and group access control, and different levels of membership and authority (member with full rights, and guest with viewing rights only)

- Support for entry of a personal profile and personalized avatar configuration for each member

- Facilities to support entry of 3D 'Discussion threads', comprising 3D sequences and steps, enabling group members to add new entries to an existing sequence, and replay entries to date in a sequence.

November 5-8, 2003, Boulder, $\mathrm{CO}$ 
Session S1F

- Support for entry of a set of avatar actions within a sequence (appear, disappear, look, walk, run)

- Support for entry of a set of avatar emotions and text discussion entries within a sequence step (wave, smile)

- Virtual world management, and server connection, data transfer between client and server environments

- Support for different camera views from the perspective of the avatar $-1^{\text {st }}$ person, $2^{\text {nd }}$ person, $3^{\text {rd }}$ person and map (birds-eye) view, within the virtual world.

The user interface design for the application is based upon a Windows style interface, with distinct areas on the screen designated for: 3D views of the virtual world; views for each step; and a control and information area for entry of new threads, sequences, steps, actions and emotions. A control menu provides access to avatar configuration, security and access information and to the different camera views.

\section{Collaborative Trial Evaluation}

As noted previously this trial has occurred as one in a sequence of trials conducted within an ongoing programme of action research into coliaborative computing, virtual groups and electronic collaborative learning groups (ECLG) $[3,6]$. A key research question related to the process of establishing trust online in a virtual or ECLG group context, using the concept of a cyber icebreaker. The distinction between $2 \mathrm{D}$ and $3 \mathrm{D}$ modes of icebreaker, and their relative effectiveness was a particular strategy for investigation within this quest.

A summary of the research programme is expressed in table 1 below using the McKay \& Marshall framework [12] "elements of an action research intervention." This problem-solving framework can prove particularly useful in giving clarity to the goals of an action research project, by distinguishing between the immediate concerns, the practice improvement goals and the particular research dimensions of an action research project.

In this case the project had its own set of teaching related goais, occurring as it did within an undergraduate teaching context. These in turn were complemented by a set of more research-oriented goals. The $3 \mathrm{D}$ application was novel and had not been proven in an intemational context, although an internal trial of the software had been conducted with some success the previous semester. A full test of the application with a large number of users had not been conducted. In this case some 130 students across both sites were to be involved in the trial, with half of the cohort to be assigned to groups within the 3D application, although the full cohort would have read access to a demonstration group within the application.

As can be seen from the research method section of the framework outlined in table 1 , a diverse set of goals and a

0-7803-7961-6/03/\$17.00 2003 IEEE broad range of data and analytical techniques could be applied to an evaluation of the project. A rationale for the techniques to be used in evaluation of the project will be further elaborated below.

TABLE I

RESEARCH FRAMEWORK FOR THE COLLABORATIVE TRIAL

\begin{tabular}{|c|c|}
\hline Element & Description \\
\hline F (Framework) & $\begin{array}{l}\text { Trust Facilitating Communication Behaviours }[8] \\
\text { Avatar-based Group Support Systems }[10] \\
\text { Extended Adaptive Structuration Theory }[11,2,3]\end{array}$ \\
\hline $\begin{array}{l}\text { MR (Research } \\
\text { Method) }\end{array}$ & $\begin{array}{l}\text { Practical Action Research } \\
\text { Field experiments } \\
\text { Quantitative Data analysis (e.g. statistical regression) } \\
\text { Qualitative Data analysis (e.g. critical incident } \\
\text { analysis) } \\
\text { Undergraduate Computing education research } \\
\text { To be determined }\end{array}$ \\
\hline $\begin{array}{l}\text { M/ (Problem } \\
\text { solving method) }\end{array}$ & $\begin{array}{l}\text { Practical Action Research, prototyping, capstone } \\
\text { software developrnent project }\end{array}$ \\
\hline $\begin{array}{l}\text { A - (problem } \\
\text { situation of } \\
\text { interest to the } \\
\text { researcher) }\end{array}$ & $\begin{array}{l}\text { - To apply the 3D collaborative database in an } \\
\text { international learning context, with distant } \\
\text { students collaborating across time zones } \\
\text { To explore the effectiveness of a cyber } \\
\text { - } \\
\text { icebreaker in developing trust in virtual groups } \\
\text { To compare the effectiveness of } 2 \mathrm{D} \text { and } 3 \mathrm{D} \\
\text { cyber icebreakers in developing trust in virtual } \\
\text { groups } \\
\text { To improve understanding of web-based } \\
\text { groupware } \\
\text { To test \& improve functionality in the } \\
\text { prototype collaborative applications } \\
\text { To evaluate the effectiveness of the design } \\
\text { concept of the 3D application and explore the } \\
\text { appropriation processes used by individuals and } \\
\text { groups } \\
\text { To evaluate the technical performance of } \\
\text { the 3D application with multiple concurrent } \\
\text { users in a collaborative trial context } \\
\text { To explore methods of linking } \\
\text { undergraduate research and teaching }\end{array}$ \\
\hline $\begin{array}{l}\text { P - a problem } \\
\text { situation in which } \\
\text { we are } \\
\text { intervening }\end{array}$ & $\begin{array}{l}\text { To enrich and broaden the student learning } \\
\text { - experience } \\
\text { To develop student capabilities in } \\
\text { teamwork, cross cultural communication and use } \\
\text { of IT } \\
\text { To develop understanding of issues in the } \\
\text { topic area of Collaboration, Communication and } \\
\text { Enterprise Support including issues to do with } \\
\text { group process and group decision-making. } \\
\text { To demonstrate some of the business, } \\
\text { human and IT issues related to creating and } \\
\text { maintaining effective virtual intermational teams } \\
\text { in organisations. } \\
\text { To develop students' technical competence } \\
\text { by becoming familiar with web based } \\
\text { groupware, its uses and limitations in an o } \\
\text { leaming context } \\
\text { To use groupware concepts to assist } \\
\text { collaborative learning across boundaries of time } \\
\text { and space }\end{array}$ \\
\hline
\end{tabular}

November 5-8, 2003, Boulder, CO

\section{$3^{\text {rd }}$ ASEE/IEEE Frontiers in Education Conference}

S1F-3 


\section{Session S1F}

\section{Data ANalysis \& Rationale}

As indicated in table 1 above, a variety of research methods and analytical techniques could be applied in evaluating the rich body of data resulting from the trial. This analysis in turn w ould be conducted within the meta-framework of an action research methodology, with its four primary steps or 'moments' of: plan, act, observe, reflect [14], expressed alternatively in [13] as diagnosing, action planning, action taking, evaluating and specifying learning.

In a collaborative research venture combined with a teaching/learning activity such as this, the goals for both dimensions tend to overlap, creating a complex context in which to perform meaningful evaluation. The multiple forms of data available for analysis as a result of the trial, encompass: broad historical and contextual data related to the initiative and within which the action research programme is situated; process related data relevant to the research, teaching and learning and the collaborative trial process; empirical forms of data such as the information supporting the operational trial, database contributions by students and on-line questionnaire responses; evaluative forms of data representing the reflective and critical moments of action research. Much of this data remains to be reviewed in full, and the forms of data with wider scope such as contextual and historical, or evaluative may be best interpreted through some form of critical method $[14,15]$. The scope of this analysis bears more directly upon the empirical data. Apart from the initial goal of proving the functioning of the prototype software, the particular emphasis of this study has related to the effectiveness of the cyber icebreaker in developing trust in virtual groups and the comparative effectiveness of the two and three-dimensional forms of icebreaker.

\section{PReliminary Findings}

Space precludes a full analysis of the trial outcome in this paper, but some preliminary findings can be reported.

\section{Prototype Collaborative Software}

The Lotus Notes ${ }^{\mathrm{TM}}$ application, although somewhat inelegant, is now relatively stable after earlier versions have been used in several previous trials. It functioned adequately throughout the trial, with relatively low technology demands, requiring only a browser at the client side for access. The avatar client software was successfully installed at both sites, and the server was established at the A uckland site. This was a relatively complex process with a full classroom of 25 Windows NT desktop images having to be updated with the client software. This necessitated rescheduling of the other sections of the class into the same room. In the previous semester the images had quickly become corrupted, leaving only a few working machines, so the author worked with the on-site technician to build some self-repair capability into the local install. Although the application itself was written in Jaya, using the Java3D API, the backend database was Microsoft Access. This had given rise to initial concerns about the likely performance of the application under load. Some issues had been noted in the previous internal trial, but the instability of the installs had led to a degree of uncertainty in the fault diagnosis. The issues became more apparent in this trial, with some negative student comments relating to 'Teamlink' (the avatar based application) in a post-trial in-class review.

"The Teamlink was fun when first started. However it was nearly unusable because not only it was slow, quite often the screen froze".

This however was balanced by the positive comment:

"If the technology was more reliable, it would have been a good experience to be in a virtual team".

An analysis of the database nevertheless indicated that in each group individuals from both locations had managed to make several avatar entries, and introduce themselves to their fellow group members, as characters actively maneuvering in the virtual room. The frustrating lack of diagnostics available made it virtually impossible to deduce the reasons for the performance issues, for instance, whether they r esulted from lack of m emory ( $256 \mathrm{MB}$ ) at the client level, MS-ACCESS database performance bottlenecks or occasional glitches within the university networks. In only a few cases were the concerns raised traceable through message logs to an actual application error.

\section{Student Preferences}

Analysis of student rankings indicated some variability of opinion over the relative effectiveness of the two different forms of icebreaker. Selected student comments are given below:

"the Avatar Based software was inadequate and very slow. Impassible to use if you want to communicate with human beings over a network".

The Notes forms based icebreaker seemed to be only slightly more popular (most groups chose the icebreaker. they were assigned to as their preference)".

"The avatar based icebreaker is both fun and feels more efficient than the Notes based one".

"[Notes icebreaker] could be done online from anywhere - not just at University. No separate programme needed".

Discussions with colleagues who directly supervised the inclass activities confirmed that the ready off-campus accessibility of the Notes icebreaker through a browser was major plus for students. Reactions to the avatar based

November 5-8, 2003, Boulder, CO

\section{$33^{\text {rd }}$ ASEE/IEEE Frontiers in Education Conference}


icebreaker had been mixed, with some Auckland Business IT students who were not expecting to have "fun" in their course, seemingly regarding the exercise with suspicion, others becoming quite engaged and enthusiastic about the exercise, and another group experiencing great frustration as they seemed to have been singled out to be plagued by technical problems.

The quasiexperimental aspect of the evaluation required that students indicate 1) their group's preferred icebreaker and 2) their assessment of the overall preferred icebreaker, by reviewing the Notes database views, which summarised the individual evaluation entries posted by students into the database. An analysis of this data indicated a strong association between the icebreaker assigned and the icebreaker preferred, confirming the statement by the student above - 'most groups chose the icebreaker they were assigned to as their preference'. Statistically this was supported by using the phi coefficient [16] to measure the strength of the association between separate pairs of dichotomous variables representing each icebreaker treatment and preference:

- The first association - group preference and assigned icebreaker; recorded a phi value of .491 at a .007 significance level.

- The second association - overall preference and assigned icebreaker - recorded a phi value of .668 at a .000 significance level.

This final analysis of overall preferences had been designed to demonstrate the support for group decision-making afforded by the collaborative software, and to act as a trigger for students to reflect upon their own experiences. It appears to have had some success in achieving this outcome, with comments such as:

"Notes based had a lot more 0's or strong disagreements than avatar.

"But the biggest problem with these projects is still the difference in time. Because a real time icebreaker would work so much better."

\section{Student Performance and Evaluations}

Students appear to have generally performed well on the exercise, and taken the trial quite seriously, as evidenced by responses to the question "I made a serious commitment to the success of the trial" in which they rated themselves at .64 on a scale of $0-1$ (where 0 represents strongly disagree and 1 strongly agree). This question had been incorporated intentionally to assess student motivation in undertaking the tasks involved in the trial.

Completion rates on the Notes icebreaker task compared favourably with previous trials - at $55 \%$ for the Notes icebreaker activities versus $22 \%$ and $29 \%$ for 2000 and 2001 trials respectively. For the avatar icebreaker task determining completion rates is somewhat more difficult, but all groups made some form of contact with their counterparts in the virtual space.

Completion rates for the group ranking task again compared very favourably, - at $94 \%$ versus $70 \%$ and $50 \%$ for the 2000 and 2001 trials. It was gratifying to see that of the 32 country subgroups involved in the trial, only two failed to complete a preference ranking entry. This may be as a result of a more tightly coordinated trial supported by a relatively comprehensive user manual for students to follow, and dedicated coordinators for the trial at each site, supported by in-class teachers.

Evaluations of both the icebreaker and the trial overall, again saw improvement on rates achieved in previous trials, - at $65 \%$ for icebreaker evaluation and $30 \%$ for final evaluation, versus 2001 figures of $50 \%$ and $30 \%$ respectively. Thus results at this level are most encouraging. Analysis of student evaluations however indicates a somewhat more complex picture. These evaluations were conducted using Notes forms in the collaborative database and a series of questions to which students indicated their degree of agreement, plus a free form area for suggested improvements. Icebreaker questions were intended to elicit the extent to which the exercise had helped students get to know and trust their collaborators, to help focus the trial and to assess the ease, enjoyment and learning value of the exercise.

Responses lent some support to the value of the icebreaker activity in supporting introductory social and procedural processes for virtual teams [8], by helping participants to 'get to know the other members of your virtual team' or develop 'trust through the initial social communication among the members of the team' and 'in developing a sense of shared purpose within your [virtual] group'. Table 2 below d epicts the $m$ ean response ratings to these questions using the previous agreement scale ( 0 indicating strong disagreement).

TABLE 2

ICEBREAKER INTRODUCTORY EFFECTIVENESS

\begin{tabular}{|l|l|l|l|}
\hline Question & Icebreaker & NZ & Sweden \\
\hline Know other members & Notes & .54 & .21 \\
\hline Develop Trust & Notes & .41 & .30 \\
\hline Develop Shared purpose & Notes & .59 & .41 \\
\hline Know other members & Avatar & .40 & .43 \\
\hline Develop Trust & Avatar & .41 & .43 \\
\hline Develop Shared purpose & Avatar & .47 & .45 \\
\hline
\end{tabular}

While mean response ratings differed notabiy in the case of the Notes icebreaker, there were very similar ratings between countries for the avatar-based icebreaker. Given that Swedish ratings tended to be lower overall, this is a promising indication for the $3 \mathrm{D}$ icebreaker. It may also suggest that the Swedish installation was a little more stable than the NZ one, and that infrastructure rather than application problems my be the source of the $\mathrm{NZ}$ student 


\section{Session S1F}

dissatisfaction with the avatar based icebreaker. This supposition has yet to be investigated.

Student evaluations for the other questions also appeared to differ by icebreaker option and by country. Notable differences are summarised in table 3 below:

TABLE 3

DIVERGENT ICEBREAKER EVALUATIONS

\begin{tabular}{|l|l|l|l|l|}
\hline Question & Icebreaker & NZ & Sweden & Variance \\
\hline Know & Notes & .54 & .21 & .33 \\
\hline Trust & Notes & .41 & .30 & .11 \\
\hline Share & Notes & .59 & .41 & .18 \\
\hline Easy & Avatar & .46 & .63 & -.18 \\
\hline Enjoyable & Notes & .56 & .36 & .20 \\
\hline Enjoyable & Avatar & .59 & .49 & .11 \\
\hline Leamt & Notes & .45 & .22 & .23 \\
\hline Leamt & Avatar & .46 & .30 & .16 \\
\hline Committed & Avatar & .69 & .56 & .13 \\
\hline
\end{tabular}

Overall the NZ groups appeared to prefer the Notes icebreaker, and the Swedish groups the avatar based icebreaker, although ratings from both countries were more even for the avatar based icebreaker, the higher commitment of the NZ groups appears to reflect an overall difference in ratings between the countries. The $3 \mathrm{D}$ icebreaker was perceived as more enjoyable to use by both sets of students, in spite of the frustrations encountered in its use.

\section{Conclusions}

This paper has reviewed an international collaborative trial in which students from New Zealand and Sweden have evaluated two different cyber icebreakers, one using a forms based 2D approach with Lotus Notes and the other a 3D personalized avatar based approach, in which collaborators meet asynchronously in a virtual room. The software and the process of the collaborative research have been described and preliminary analysis of the empirical data has been conducted. While some performance and infrastructure issues have clouded the situation the 3D application appears to have injected an element of fun and excitement into student learning, and show some promise as an approach for initiating new members into a virtual team. The flexibility of the Notes browser based application has proven a counter to this argument, with the complexities of client server configuration a clear drawback for Java 3D applications. Diagnosis of performance problems in such environments is non trivial, and requires the support of knowledgeable technical staff, or a set of diagnostic routines in the $3 \mathrm{D}$ collaborative application itself. Developing this diagnostic software is the next step planned for this continuing action research programme, in which the complex world of virtual teams is being explored.

\section{ACKNOWLEDGEMENT}

The forms-based cyber-icebreaker task was developed based upon a concept originally suggested by Elyssebeth Leigh from the University of Technology at Sydney. The work of Graeme Foot in developing the 3D icebreaker application must also be acknowledged, together with that of Anne Philpott his project supervisor.

\section{REFERENCES} 2002, Auckland, 2002.

T. Clear, "Genre Structuring In a Web-based Groupware Medium: The Evolution of a Project Progress Report," presented at 19th Annual Conference of the Australasian Society for Computers in Leaming in Tertiary Education (ASCILITE)

T. Clear, "International Collaborative Learning - The Facilitation Process," presented at ED-MEDIA " 99 - World Conference on Educational Multimedia, Hypermedia and Telecommunications, Seattle, Washington, 1999.

[3] T. Clear and M. Daniels, "Using Groupware For International Collaborative Learning," presented at The 30th American Society for Engineering Education/Institute of Electrical and Electronics Engineers Frontiers in Education Conference 2000, Kansas, Missouri, 2000.

[4] T. Clear and M. Daniels, "A Cybericebreaker for an Effective Virtual Group?," presented at The 6th Annual Conference On Innovation and Technology in Computer Science Education (ITiCSE), University of Canterbury, Kent, 2001.

[5] T. Clear and G. Foot, "Avatars in Cyberspace - A Java 3D Application to Support Performance of Virtual Groups, ${ }^{\text {" }}$ presented at Innovation and Technology in Computer Science Education, Aarhus, Denmark, 2002.

[6] E. Fahraeus, B. Chamberlain, N. Bridgeman, U. Fuller, and J. Rugelj, "Teaching with Electronic Collaborative Learning Groups," in ITICSE Working Group Reports, SIGCSE Bulletin. New York: ACM, 1999, pp. 121 - 128.

[7] G. Foot, "Functional Specification - Project 7 Cyber Icebreaker," Auckland University of Technology, Auckland, Unpublished Technical Report 2001.

[8] S. Jarvenpaa and D. Leidner, "Communication and Trust in Global Virtual Teams," Joumal of Computer Mediated Communication, vol. 3, 1998.

[9] NIDA and EML, "Stagestruck," vol. 2003: Educational Media Lab University of Wollongong, 2001.

[10] J. Nunamaker, "Future Research in Group Support Syst ems," International Journal of Human -Computer Studies, vol. 47, pp. $355-356,1997$.

[11] G. DeSanctis and M. Poole, "Capturing the Complexity in Advanced Technology Use: Adaptive Structuration Theory," Organization Science, vol. 5, pp. 121 - 147, 1994.

[12] J. McKay and P. Marshall, "2x6=12, or Does it Equal Action Research?," presented at Australasian Conference on Information Systems, Wellington, 1999.

[13] G. Susman and R. Evered, "An Assessment of the Merits of Scientific Action Research," Administrative Science Quarterly, vol. 23, pp. 583-603, 1978.

[14] W. Cart and S. Kemmis, Becoming Critical: Knowing Through Action Research. Melbourne: Deakin University press, 1983. W. Orlikowski and J. Baroudi, "Studying Information Technology in Organizations: Research Approaches and Assumptions," Information Systems Research, vol. 2, pp. 1 -28, 1991 .

[16] W. Daniel, Applied Nonparametric Statistics. Boston: PWS Kent, 1990, p.401 